\title{
EXTRACTING GRAPHITE SKETCH OF THE MURAL USING HYPER-SPECTRAL IMAGING METHOD
}

\author{
Xiaomeng Han, Miaole Hou, Guang Zhu, Yuhua Wu, Xinfeng Ding
}

Original scientific paper

Many contaminants appear in murals as time passes, which make the original mural blurred and difficult to recognize; therefore, extracting a clear graphite sketch of the mural is significant. In this study, we used invisible spectra, particularly near-infrared (NIR) bands, to detect the graphite information and strengthen the features of the mural information to obtain a graphite sketch. This is the first study to extract the contour line from the draft of the mural using hyper-spectral imaging (HSI) technology. First, spectral matching methods were used to identify the pigment of the contour line and graphite was determined as the main pigment of the draft. Then, the characteristic bands were selected by analysing the spectra of the pigments. After that, the information extraction method was used to extract the graphite information. The results showed that the method could improve the efficiency of graphite information extraction significantly. The key steps of the current method involved extracting the graphite contour line end-member spectrum, followed by mapping the grey image of the graphite contour line spectrum. Finally, the visually enhanced image was reconstructed using the alpha blending fusion method with the original visible image and the graphite information image. The efficiency of results is evaluated by quantitative methods. The study also explained and discussed the two key points of election thresholds in obtaining the graphite sketch. These results demonstrate that the method is efficient for extracting graphite sketch based on hyper-spectral data of mural, and that it could provide useful information to explore cultural relics and to support some other protection researches.

Keywords: graphite contour line; Hyper-Spectral Imaging; information extraction; murals; visual enhancement

Dobivanje grafitne skice murala primjenom metode Hyper-Spectral Imaging

Izvorni znanstveni rad

Kako vrijeme prolazi murali postaju sve zagađeniji te originalni mural postaje nejasan i teško prepoznatljiv; stoga je važno dobivanje jasne grafitne skice murala. U ovom smo radu primijenili nevidljive spektre, posebice skoro-infracrvene pojaseve (near-infrared (NIR) bands), kako bismo otkrili podatke o grafitu i učvrstili karakteristične informacije o muralu za dobivanje grafitne skice. Ovo je prvo istraživanje u svrhu dobivanja osnovne linije konture iz skice murala primjenom tehnologije hiper-spektralnog slikovnog prikaza (hyper-spectral imaging (HSI). Najprije se metodama spektralne kompatibilnosti identificirao pigment osnovne konture te se grafit odredio kao osnovni pigment skice. Tada su se odabrali karakteristični pojasevi analizom spektra pigmenata. Nakon toga, metodom izvlačenja informacija dobivena su saznanja o grafitu. Rezultati su pokazali da se tom metodom mogla značajno povećati učinkovitost dobivanja novih spoznaja o grafitu. Ključni postupci ove metode obuhvatili su dobivanje spektra završnog elementa osnovne konture grafita, te mapiranje sive slike spektra osnovne konture grafita. Konačno, rekonstruirana je vizualno povećana slika primjenom alpha blending metode fuzije s originalno vidljivom slikom i slikom informacija o grafitu. Učinkovitost rezultata izmjerena je kvantitativnim metodama. U radu se također objašnjavaju i razmatraju dvije ključne točke izbornih pragova za dobivanje grafitne skice. Ovi rezultati pokazuju da je metoda učinkovita za dobivanje grafitne skice na temelju hiper-spektralnih podataka o muralu i da može dati korisne informacije u istraživanju kulturnih relikata i davanju podrške nekim drugim zaštićenim istraživanjima.

Ključne riječi: dobivanje informacija; hiper-spectralni slikovni prikaz; murali; osnovna kontura grafita; vizualno pojačanje

\section{Introduction}

Murals reflect the economic and cultural development and ideology of various historical periods from different perspectives. They not only show painting technique development in different historical periods, but also reflect development status of combination of social life, religion and art in different historical periods. Because of the threat of natural disasters and the influence of artificial factors, the colour of some mural areas has become fuzzy. If the painting cannot get effective protection, it will gradually disappear. The traditional Chinese mural production engineering is huge and has many working procedures. It is painted on the wall which is daubed on the ahead of time through thick mud, mud and lime mixture on the thick mud, mud and lime. The artisan-painter drew the draft's outline with charcoal or graphite and utilized graphite to strengthen the paint edge. The sketch can reflect the painter's original ideas directly. Therefore, extracting the contour line of a mural manuscript rapidly, accurately and scientifically has important significance for mural protection and restoration.

Hyper-spectral imaging (HSI) captures a densely sampled spectral response of a scene object over a broad spectrum, including invisible spectra such as ultra-violet (UV) and near-infrared (NIR). Hyper-spectral imaging has been employed in various scientific disciplines to provide valuable data for fields such as astronomy [1], earth sciences and remote sensing [2, 3], food safety [4], criminal investigation, and computer vision [5]. With the advances in technology and cost reductions, the hyperspectral imaging of historical art and murals is now accessible for use at mural protection and research institutes. In addition, Haneishi et al [6] in 2007 with the multi spectral technique to obtain the mural image, using the image segmentation technology to classify the area of pigments in mural painting, analysed mural pigment information. Daniilia [7] of the art diagnostic centre in 2008 analysed the Greek Meteora mural information by Raman spectroscopy and gas chromatography analysis method to provide the necessary data resources for further exploration research for historical information of the murals. Chai [8] acquired image data of Mogao Grottoes 194th cave murals by using multispectral technology. He compared UV fluorescence imaging with visible light images to obtain drawn information from the murals. Hain et al. [9] captured an image of an oil painting using multispectral imaging technology, and extracted draft information that could not be detected by the naked eye 
under natural light conditions. Kim et al [10] used HSI to enhance the visualization of an old document. The advantage of HSI is that it provides detailed and ample data, including spatial and spectral information. Lu [11] proposed efficient algorithms to acquire and process visual exemplars and a general framework for data-driven stroke synthesis based on feature matching and optimization. Zhang [12] proposed an enhancing algorithm to lessen the iteration numbers and utilized graphics processing units (GPUs) to shorten the computational time per iteration. The experiment demonstrated that both the end member extraction accuracy and the computational performance of ACOEE benefited from the method. Lau [13] introduced a new approach to imaging elemental data from energy dispersive X-ray analysis maps, the method was used in conjunction with micro-Raman spectroscopic imaging to characterize the paint layers within micro-samples. Dópido [14] conducted a quantitative and comparative assessment of unmixing-based versus traditional (supervised and unsupervised) feature extraction techniques in the context of hyper-spectral image classification. Hou [15] proposed a novel technology method to restore the heritage relic.
Therefore, HSI can accurately extract and analyse mural components such as draft lines and destroyed pigments.

Hyper-spectral technology is useful for many tasks related to mural conservation and management, because it provides detailed quantitative measurements of the spectral reflectivity of the mural. This makes HSI more suitable for tasks that require accurate quantitative measurements, such as conservation, detecting damage, analysis of materials in the mural (e.g. pigments), and changes over time due to aging. In addition, HSI provides measurements in the invisible spectra (NIR and UV), which further enrich the analysis and enhance the data and provide useful information about the mural that sometimes cannot be seen in the visible range. This is highlighted by two examples in Fig. 1. In the first example, the NIR band at $750 \mathrm{~nm}$ provides more contour line detail than does the image in the visible band (450 $\mathrm{nm}, 550 \mathrm{~nm}, 650 \mathrm{~nm})$. In the second example, the NIR band image at $1500 \mathrm{~nm}$ is better for recognizing the pattern than is the visible image, since contaminants such as water rust and dirt are less influential in the infrared band. Fig. 1 clearly described the difference between the visible light image and hyper-spectral images. a)

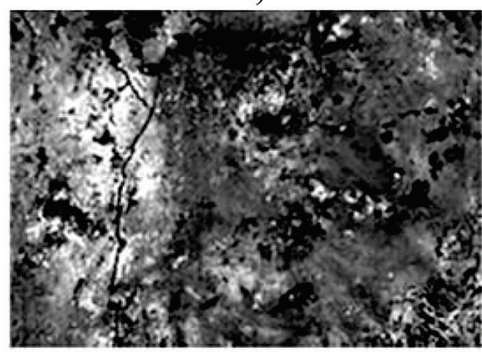

d)

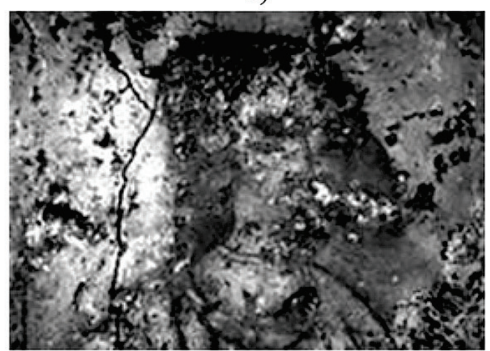

b)

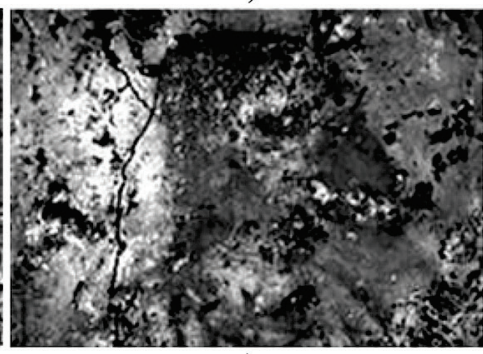

e)

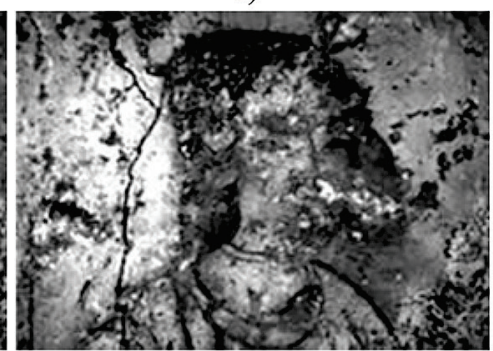

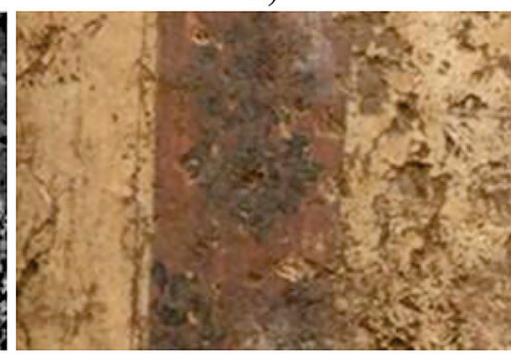

f)

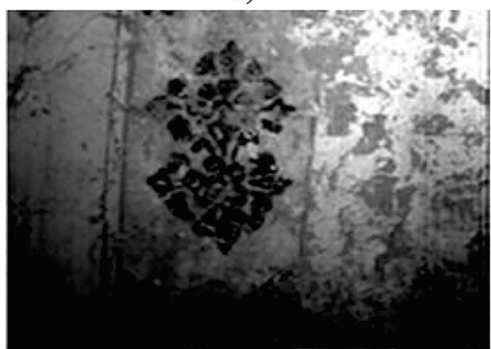

Figure 1 Hyper-spectral images: a) $450 \mathrm{~nm}$; b) $550 \mathrm{~nm}$; c) original visible light image; d) $650 \mathrm{~nm}$; e) $750 \mathrm{~nm}$; f) $1500 \mathrm{~nm}$

The aim of this study was to use hyper-spectral images of murals to visually enhance the mural's graphite contour line information. HIS was applied to an RGB image of the hyper-spectral data from an original visible image, because the RGB image is the most natural visualization of the data. For murals that are destroyed by water, rust, dirt, plant roots, and damage caused by insects, infrared bands were used, which capture much less contamination than do visible bands, to extract graphite information and remove the contamination from the murals. The final image was enhanced using image fusion, which can highlight graphite information and also reduce information caused by contaminants.

The paper is organized as follows: we begin by introducing background of the study which concludes the data research demand, related research review and parameter of experimental data. Section 2 describes the method used for graphite sketch extraction, including the principle of the method and the practical process. The process of pigment identification and graphite information extraction are introduced in Section 2. In Section 3, we present the experimental results and compare our outcome images with the original image using quantitative evaluation methods. We also explore the different influence of methods in information extraction in Section 4. Finally, we conclude a discussion of our method and future directions in Section 5.

\section{Methodology}

The aim of the method is to acquire a graphite sketch of the mural, which can reflect the original design idea of painter, and it can restore the initial appearance of the mural removing the damaged interference by age. First, the graphite distribution area (contour line) was selected as the region of interest, the part of mural's contour line 
was selected as the research object, the pigment of the contour line would be identified based on the feature of spectrum by using binary encoding algorithm, spectral angle classification and spectral feature fitting classification, the matching degree $(M)$ was utilized to evaluate the accuracy standard of spectrum matching result. Second, after knowing the graphite was the main pigment of the contour line, we collected all the pigments used in the mural, compared and analysed the graphite spectral feature characteristic among the other pigments. According to the different reflection properties of pigments in the specific bands, the characteristic bands which are sensitive to reflection of graphite were selected for information extraction. Third, an ideal target image of the contour line based on graphite information was obtained by using a series of extraction methods. It included the pure end member collection, selection and spectral classification. The final step was image fusion: in order to complete and enrich the sketch and reduce the damage at the same time, alpha blending fusion was used to achieve perfect image result. Alpha blending fusion was performed between the graphite sketch image and the visible light image. The final fusion image (graphite sketch) revealed effective image enhancement.

\subsection{Identifying the pigment of contour line}

Using VNIR400H hyper-spectral camera, the program obtained the hyper-spectral data of mural which had $0,6 \mathrm{~nm}$ spectral resolution and range from $400 \div 1000$ nm. The process flow is shown in Fig. 2. Firstly, we selected a region of interest of the contour line in the manuscript based on the abundant hyper-spectral information. Then, the spectrum curve of the contour line was extracted and the average spectrum curve was acquired through calculation. At last, we matched the average spectrum with the mural pigments library for material identification. The matching degree $(M)$ was the introduced to describe the spectrum matching similarity.

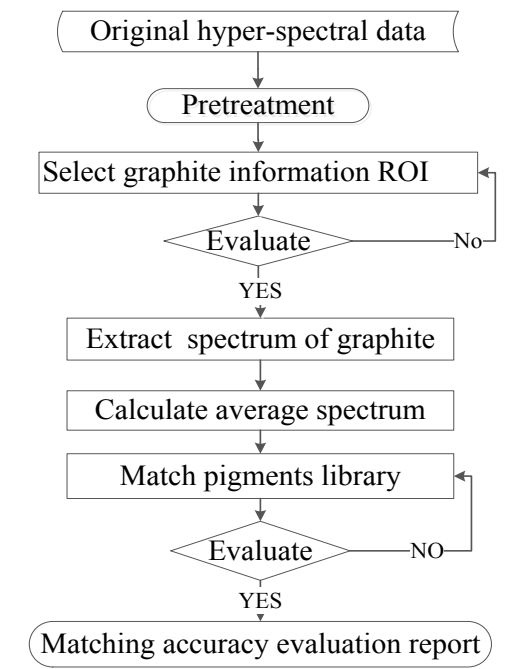

Figure 2 The flow of pigment identification process

We matched the experimental area spectrum with the standard pigments spectral library and utilized the matching degree $(M)$ to evaluate the accuracy of the experimental spectrum, which is the standard for accessing the result of three match calculations. The value of the matching degree was calculated by the following formula. The higher value represented the higher matching similarity with the pigment spectral library.

$M=x \cdot a+y \cdot b+z \cdot c$.

$M$ is calculated to give the spectral matching similarity when combining three algorithms; binary encoding algorithm, spectral angle classification and spectral feature fitting classification. $a, b$ and $c$ are the weighted values of each algorithm respectively. $x$ presented the value of binary encoding algorithm result. The band value fluctuated around the average value, binary coding technology coded the experimental area spectrum and end-member spectrum using 0 and 1 respectively (if the original value was higher than the average value, then using 1 instead, otherwise using 0 ). In the process of encoding, the algorithm was used for encoded spectrum data with the reference to standard spectrum. $y$ presented the value of spectral angle classification result. Spectral angle classification was a kind of algorithm based on spectral classification method. The method matched the experimental spectrum with the standard reference spectrum in the $N$-dimensional space. The smaller angle indicated that the pixel spectrum was matched with the reference spectrum closely. $z$ presented the value of spectral feature fitting classification result. The spectral feature fitting technology is a kind of classification based on the absorption characteristics. We calculated the image spectrum fitting ratio with the reference spectrum by using the least squares fitting technique. After the continuum was removed from both data sets, scale the data consulted to the standard spectrum so as to match the image spectrum. Spectral Feature Fitting (SFF) was used to compare the fit of image spectra to reference spectra using a least-squares technique. SFF was an absorption-feature-based methodology. The reference spectrum was scaled to match the image spectra after the continuum was removed from both data sets.

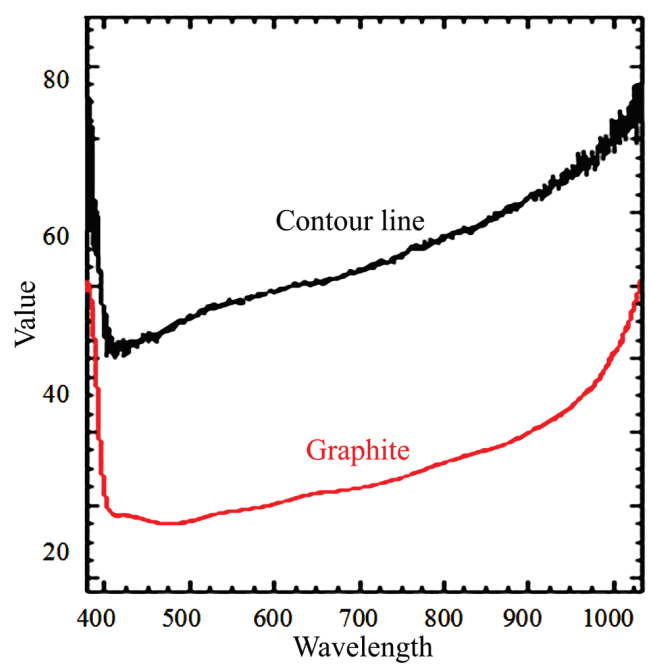

Figure 3 Pigment identification result of contour line

In this study, $a, b, c$ were given the equal value. With the pigment spectral library as reference, we selected an 
experimental area of graphite contour spectrum to match and analyse. The formula was used to calculate the spectrum similarity by three kinds of matching algorithm, the assessment results of material components as follows.

Table 1 The graphite matching similarity

\begin{tabular}{|c|c|c|c|c|}
\hline Algorithm & $\begin{array}{c}\text { Binary } \\
\text { encoding } \\
(X)\end{array}$ & $\begin{array}{c}\text { Spectral } \\
\text { angle } \\
\text { mapper }(Y)\end{array}$ & $\begin{array}{c}\text { Spectral } \\
\text { feature } \\
\text { fitting }(Z)\end{array}$ & $m / \%$ \\
\hline Score & 0,861 & 0,911 & 0,936 & 90,3 \\
\hline
\end{tabular}

As shown in Tab. 1, matching the experimental data with all kinds of pigment material spectrum, graphite arrived at the highest similarity of $90,3 \%$. Therefore, the result revealed that graphite was the main composition of the contour line in the experimental area (Fig. 3).

\subsection{Selecting the characteristic bands based on the features of graphite}

To characterize the pigments reflected in the NIR bands, all kinds of pigments used in the ancient mural paintings were collected after consulting IFAC, all the pigments used in the experimental mural were displayed on a template as shown in Fig. 5, Fig. 4b showed their $900 \mathrm{~nm}$ infrared image. The corresponding names of the pigment templates are shown in Tab. 2 .

Table 2 Laboratory pigment templates

\begin{tabular}{|c|c|c|c|c|}
\hline & 1 & 2 & 3 & 4 \\
\hline 1 & Ochre & Cinnabar & Red lead & Madder \\
\hline 2 & Sienna & Gamboge & Realgar & Orpiment \\
\hline 3 & Malachite & Azurite & Graphite & Indigo \\
\hline 4 & Chalk & Lead white & Gold & Silver \\
\hline
\end{tabular}

a)

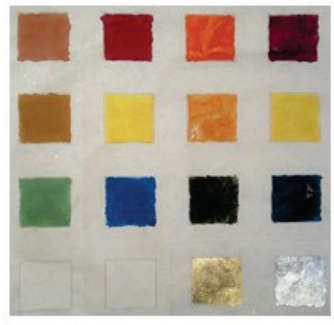

Figure 4 Template infrared images of the pigments show obvious performances differences among pigments: a) visible image; b) $900 \mathrm{~nm}$ infrared image

The pigment template hyper-spectral data were captured by using the Themis T-FPS2500 infrared hyperspectral image device, which has a spectrum range of 800 $\div 2500 \mathrm{~nm}$. The NIR template image (Fig. 4) revealed that graphite performed differently from other pigments, which explained why the sketch of paintings based on graphite is seen clearly in NIR images. The range of NIR is $700 \div 1000 \mathrm{~nm}$, and NIR electromagnetic waves can bypass dirt and water rust on mural's surface to subsequently explore the sketch detail in the mural; it was very valuable and important for protecting and restoring murals. As shown in the NIR image, the colour of graphite reflected more deeply than other pigments; therefore, graphite had the maximum absorption. The special performance of graphite allows contour line to be extracted from a painting using infrared band and the mural sketch to be obtained.

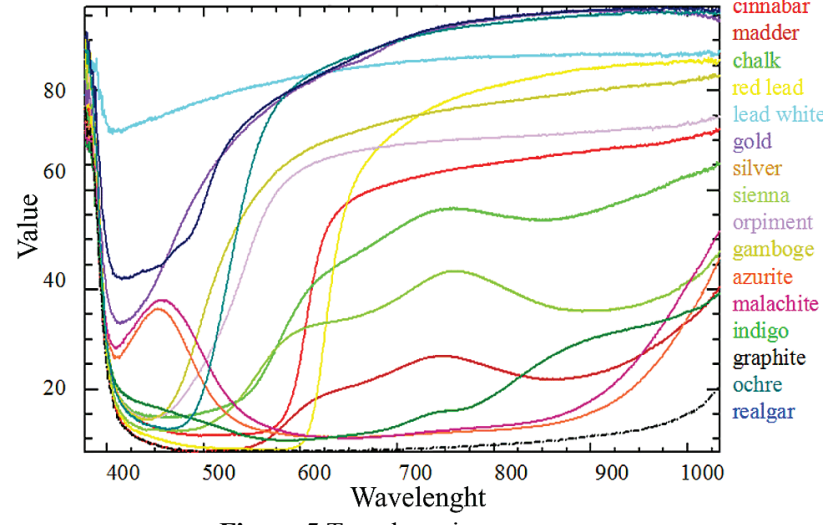

Figure 5 Template pigment spectra

Fig. 5 showed the reflection of all the different Chinese pigments. Among the numerous pigments, the graphite in every band was relatively stable compared with the other pigments and the deflection was the lowest; therefore, it had a stronger absorption than the other pigments. In particular, the reflection of graphite, azurite, and malachite had obvious differences in the $700 \div 1000$ $\mathrm{nm}$ bands; therefore, graphite could be distinguished from the other pigments in the infrared bands. Therefore, we selected $700 \div 1000 \mathrm{~nm}$ band as the feature band to extract the contour line based on graphite information from the feature bands effectively and realize the maximum reduction of the mural draft. The special performance of graphite allowed us to collect the contour line pixels of a painting using the infrared band and obtain the graphite information to meet expectations.

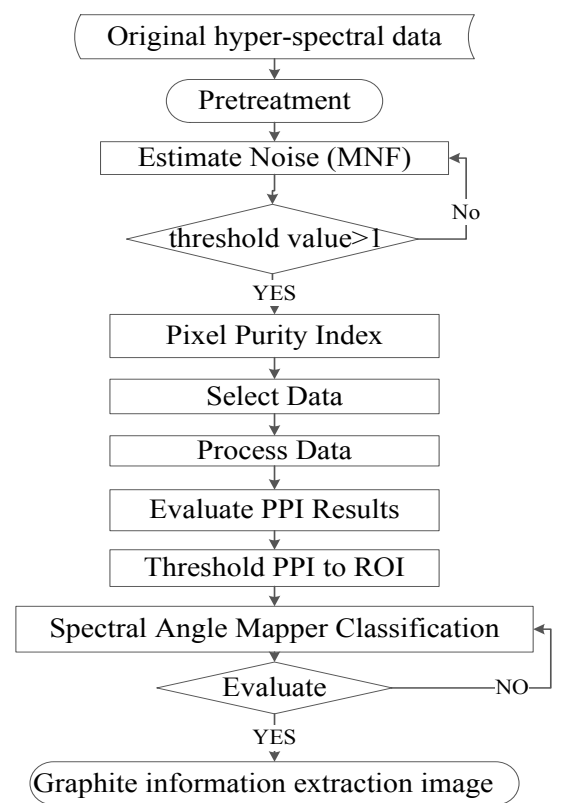

Figure 6 The framework of graphite information extraction

\subsection{Extracting the graphite information}

The graphite sketch was extracted via a process involving three steps: contour line based on graphite information end-member spectra extraction, extracting the draft based on the spectral characteristics of graphite, and selecting the framework of graphite information extraction, as shown in Fig. 6. 


\subsubsection{Extracting the end-member of graphite information image}

Graphite spectra extraction involved two steps: data reduction and end-member extraction. Data reduction was important because the large amounts of hyper-spectral data included not only had redundant noise information, but also required additional computing time during the subsequent processing. The HSI of mural was converted by the Minimum Noise Fraction (MNF) method for separating the noise from useful information $\mathrm{MNF}$ transforms, segregates, and equalizes noise in the data, and also reduced the data dimension for target detection processing. The resulting bands in the MNF transformed data are sorted by spatial coherence in descending order. Lower MNF bands typically had spatial structure and contained most of the information. Higher MNF bands typically have little spatial structure and contained most of the noise. Fig. 7 showed the results images of MNF transform processing. The first principal component image of the MNF transform was selected, because it contained the most effective information from original image and was used as the fundamental data for the next step of pure pixel extraction. a)

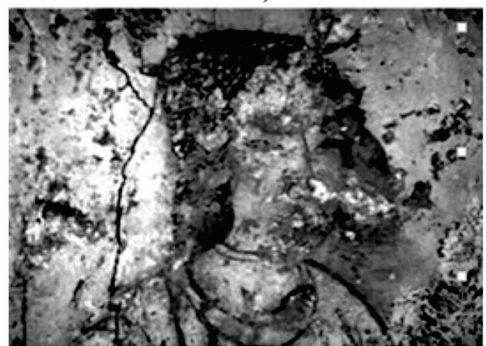

b)

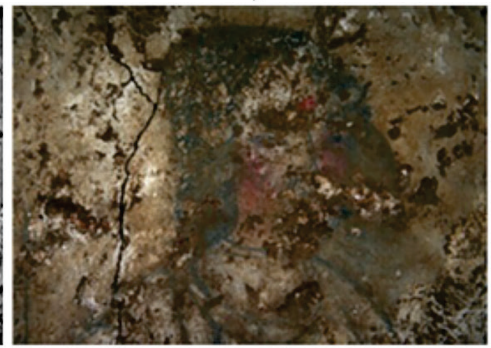

c)

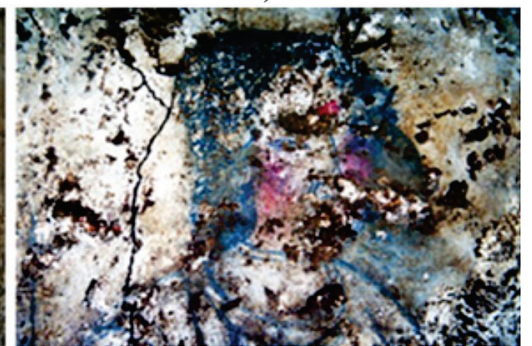

Figure 7 MNF transform processing images: a) first principal component image of MNF transform; b) visible light image; c) MNF color image

Before graphite contour line end-member extraction, the Pixel Purity Index (PPI) was calculated using the MNF principle component image. PPI indicates the most extreme pure pixels in multicultural and hyper-spectral images. These typically correspond to mixing endmembers. The PPI was computed by repeatedly projecting $n-D$ scatter plots onto a random unit vector. The Environment for Visualizing Images (ENVI) by ITT VIS (Visual Information Solutions) in US records the extreme pixels in each projection and it records the total number of times that each pixel is marked as extreme. A PPI was created where the value of each pixel corresponds to the number of times that each pixel was recorded as extreme. The conventional end-member extraction was performed using the n-D Visualizer tool (Fig. 8a), but this was not suitable for high-resolution hyper-spectral data. Therefore, we set the threshold of the PPI image and then obtained the region of interest (ROI) of accurate pure pixels simultaneously. Each pure pixel was marked artificially in the same colour (Fig. 8b) so that the pure pixels of contour line could be selected manually to make a ROI in the infrared bands. Finally, the mean spectra of all pixels in the ROI of the graphite contour line were calculated based on whole range of hyper-spectral data. a)

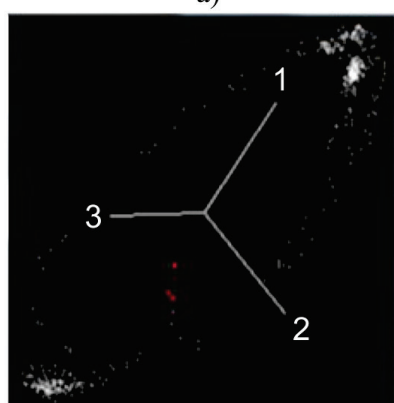

b)

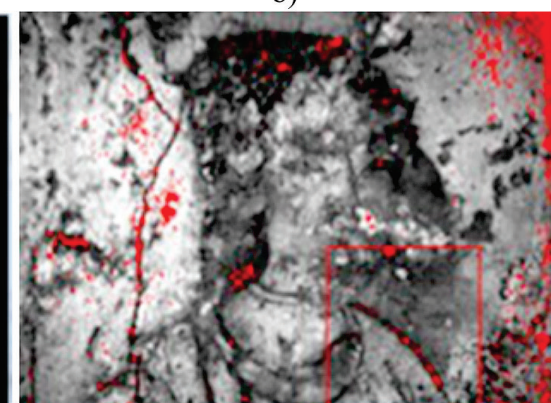

c)

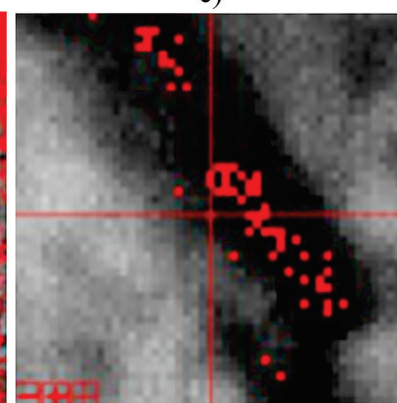

Figure 8 The framework of the selected Pure pixels: a) $n-D$ visualizer tool; b) whole infrared image with PPI; c) zoom image with pure pixels

\subsubsection{Extracting the graphite sketch based on the SAM classification}

After obtaining the MNF image, image classification was used to extract the graphite information to highlight the draft. An ideal draft image should have two features: ample information (such as graphite contour line) should be presented, and other unrelated information (such as contamination) should be minimal. Although the infrared band image could show graphite information, some contamination such as cracks and dirt were close to the graphite information available in the original infrared image (Fig. 9). Therefore, the infrared picture was not an ideal image for fusion. In the current study, we used the SAM algorithm as the most appropriate algorithm to extract graphite contour line information and obtained the graphite sketch image.

Spectral Angle Mapping (SAM) is a type of spectral classification based on physics, which used $N$-dimension angles to match an end-members spectrum with the reference spectra. The spectrum was considered to be a space vector, in which the dimensions were equal to the 
number of bands. The spectral similarity value was calculated by comparing the angle of the reference spectral vector and each pixel in the $N$-dimensional space vector.

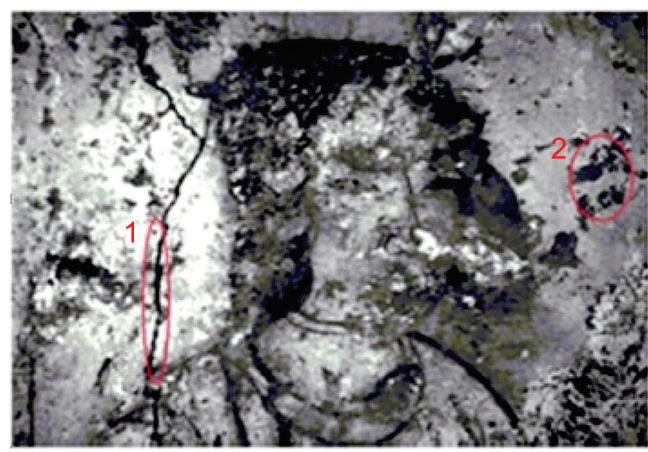

Figure 9 Original infrared image

a)

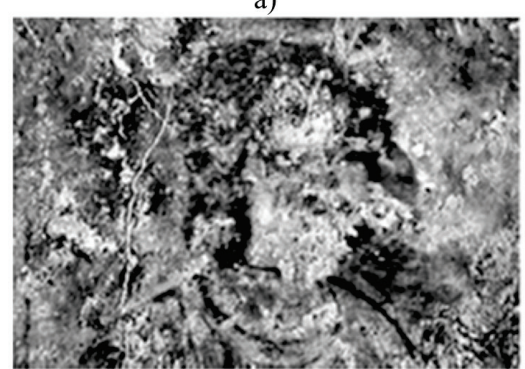

Figure 10 SAM classification images: The original infrared image is cracked and has dirt information that cannot be distinguished with the contour line; however, the grey image of graphite line could separate them well. a) grey image of graphite contour line extraction; b) colour image of SAM classification.

\subsection{Image fusion alpha blending method}

Murals are the epitome of colourful history culture; therefore, people usually respect the original unearthed cultural relics and emphasize that murals should reduce redrawing artificially as much as possible during restoration. Considering the protection principle, the alpha blending method was used for image fusion to enhance the graphite information. The alpha channel ( $\alpha$-channel) determines the transparency of an image. The $\alpha$ - channel value is standing for opacity. The $\alpha$-value can assign a contribution weight to the red, green and blue channels for every pixel, and is between 0 and 1: $\alpha=1$ means opaque, $\alpha=0$ means entirely transparent, and a middle value means partially transparent. Alpha blending first separates the RGB channels of the original image and the
The SAM algorithm extracts and calculates the average spectrum from the image as a classification reference. We calculated each pixel vector and the reference spectral vector to obtain the generalized angle, a smaller angle means greater similarity and good quality matching with the reference spectra. If the radian angle of pixel matching was larger than 0,1 , the pixels will not be classified any more. This method made full use of spectral information, and emphasized the shape characteristics of the spectrum. Therefore, the spectrum of the graphite line was taken as the reference spectrum. The calculating result showed the spectral similarity value with the graphite contour line. The value of graphite information approached 0 , and the smaller the grey value, the closer the pixel was to graphite information. The results showed that the graphite information was obviously distinguished, but other contamination information (such as cracks and dirt) was weak (Fig. 9). b)

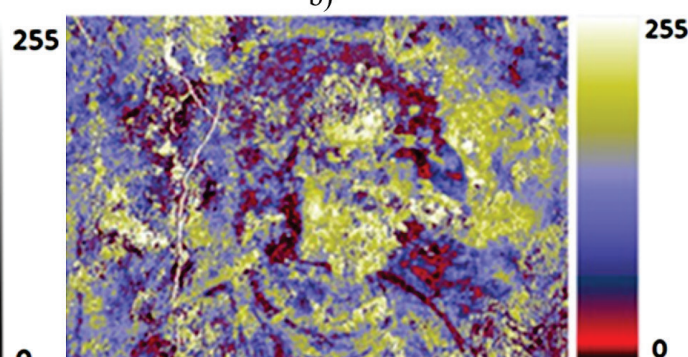

a)

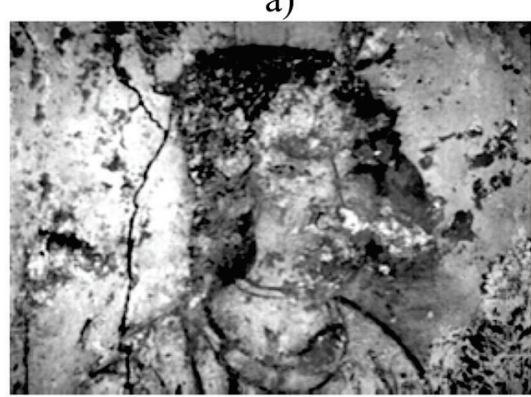

b)

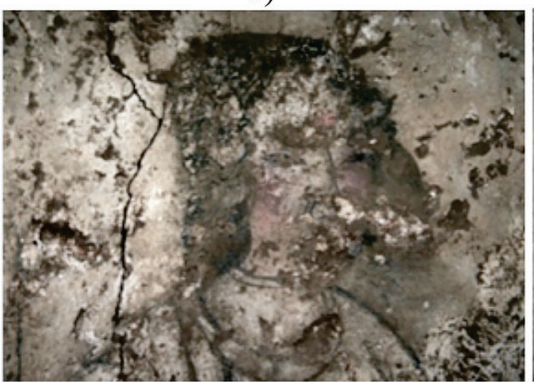

c)

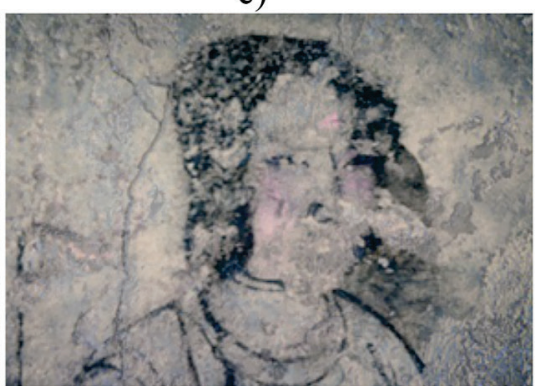

where $d s t_{x, y}$ is the final fusion image, $\alpha$ is the transparency factor, $\operatorname{src}_{1 x, y}$ is the original image, and $\operatorname{src}_{2 x, y}$ is the target ink line extraction image. The use of alpha blending by adjusting the $\alpha$ factor allows the original colour of the mural to be retained to the largest degree. Therefore, the key is finding the second ideal image to be fused.

Figure 11 Fusion images: a) the original infrared image; b) traditional fusion image; c) alpha blending fusion image 


\section{Experimental results and analysis 3.1 Experiment area}

In this study, we selected the experimental area from western wall in the Liuji tomb. We selected a $60 \times 60 \mathrm{~cm}$ area on the mural as the experimental area. We then used two HSI cameras (VNIR400H and T-FPS2500) to capture the data. The instruments were composed of an automatic scanner, a spectrometer, and an image sensor, which could correct the spectrum accurately. The VNIR400H HSI device is produced by Themis Corporation (103 floors 143A Room, 39529-0001NASA Stan's space center, Mississippi in the United States, the internet www.themisivision.com) and captures images at different wavelength bands from $370 \mathrm{~nm}$ (UV) to $1040 \mathrm{~nm}$ (NIR) with the step size of $2,8 \mathrm{~nm}$. The images have a resolution of 1 mega pixel $(1392 \times 1000)$ for a physical surface area of $260 \mathrm{~mm} \times 260 \mathrm{~mm}$, and are captured at 14 bits per pixel. Such high-resolution (30 pixels per $\mathrm{mm}^{2}$ ) provides reliable spatial measurements that are suitable for even thin lines on murals. The abundant available spectral data provide a sufficient database for the graphite contour line information extraction. a)

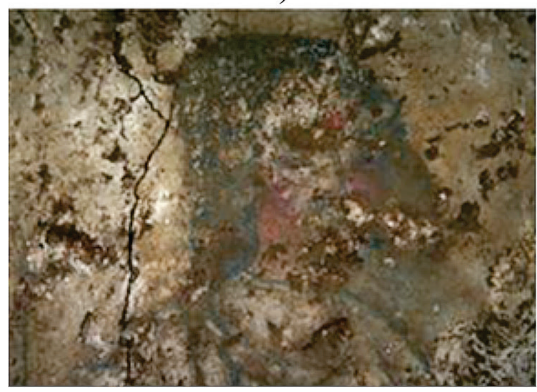

Figure 12 Contour extraction images: a) the original visible light image; b) a fusion image of the original RGB image and a graphite information extraction image; c) butterfly pattern

\subsection{Comparison}

As shown in Fig. 12a visible light image is captured in the tomb, which is the closest to the current actual appearance of mural which people observed, the character of contour lines in the original image is unclear obviously, with the passage of time it encountered serious damage by nature and human destroying. As shown in Fig. 12a, we cannot distinguish the true draft under the surface of mural. After image processing, the graphite sketch is obtained based on the fusion of original visible image and graphite contour line extraction image. Experiments revealed that the transparency factor is acceptable when the $\alpha$-value is between 0,5 and 0,7 . The final fusion image used an infrared image or ink line rule image with $\alpha=0,5$, the terminal fusion image is shown in Fig. 12b. The final fusion image strengthens the graphite contour line of character, especially the facial features of the women in Fig. 12b are clearly seen. The clothing silhouette and characters' expressions are clearly visible in the image in Fig. 12b. Particularly the butterfly pattern on hair, which cannot be seen in the original image, is clear in Fig. 11c. The graphite sketch (the final fusion image) cannot only effectively weaken the information such as wall cracks, dirty but also strengthened the graphite contour line information. The results presented here demonstrated a novel information extraction method based on hyper spectral data that is efficient for showing the sketch of the mural.

\subsection{Evaluating the efficiency of graphite contour line extraction based on DN value evaluation method}

In order to quantify the effect of graphite line extraction, we proposed an approach based on the band math algorithm to assess the enhancement of the mural. Generally, every image has its own unique band information and special rules of patterns. First, we select 6 experimental areas in the graphite sketch which has contour line information, as shown in Fig. 13.
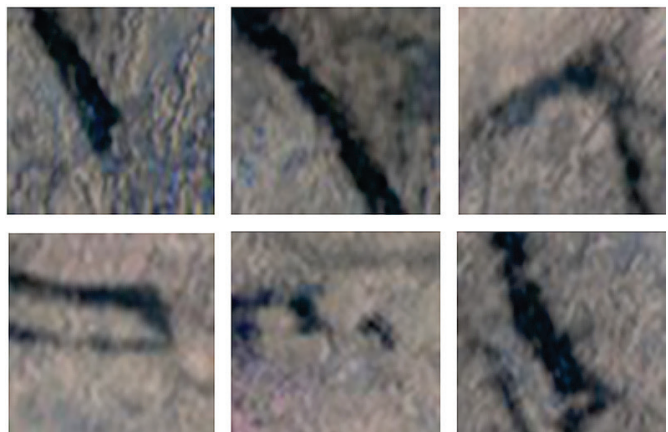

Figure13 Samples of graphite contour line image

The goal of using the image operation method for band calculation was to magnify the differences between the original visible light images (Fig. 14b) and the graphite sketch (Fig. 14a). In practice, calculating the corresponding pixels in the two images: the $\mathrm{DN}$ values of the original image minuses the value of graphite contour extraction image. Fig. $14 \mathrm{c}$ is grey image derived from the band math result. We acquired a new grey result image after band calculation, in which the grey value represented the result of the image operation. The grey value ranged from 0 to 255 , where values approaching 0 and 255 reflected black and white in the image respectively. A grey image of band math result is shown in Fig. 14c, which represents the change of $\mathrm{DN}$ value between visible light image and graphite sketch, the value of the pixel in Fig. 14c approached zero showing that grey value change was smaller. Conversely, the part of white background indicated that the difference between two images was obvious. Therefore, the contour line based on graphite information was extracted and strengthened, 
which retained the maximum graphite information from the original image. In order to detect the change and quantitative analysed scientifically, we computed the band operation results and listed the change DN value of the two pictures in Tab. 3. The value results of band math calculation were equal classified to 9 degrees (Tab. 4).

Table 3 Class change detection

\begin{tabular}{|c|c|c|c|}
\hline Class name & $\begin{array}{c}\text { Original image } \\
\text { (mean grey } \\
\text { value) }\end{array}$ & $\begin{array}{c}\text { Graphite } \\
\text { information } \\
\text { image (mean } \\
\text { grey value) }\end{array}$ & $\begin{array}{c}\text { Mean } \\
\text { value }\end{array}$ \\
\hline Change (+4) & 240,1 & 26,4 & 133,25 \\
\hline Change (+3) & 214,5 & 60,7 & 137,6 \\
\hline Change (+2) & 176,6 & 84,3 & 130,45 \\
\hline Change (+1) & 129,2 & 98,8 & 114 \\
\hline No change & 100,7 & 100,7 & 100,7 \\
\hline Change (-1) & 96,8 & 125,2 & 111 \\
\hline Change (-2) & 83,7 & 175,6 & 129,65 \\
\hline Change (-3) & 59,5 & 214,4 & 136,95 \\
\hline Change $(-4)$ & 23,2 & 246,3 & 134,75 \\
\hline
\end{tabular}

We can also explore the positive and negative correlation between the changes based on the data provided in Tab. 4 . The percentage of change above 0 was far more than was the change below $0(57,02 \%$ and $42,45 \%$ in Fig. 15, respectively). Therefore, the methods enhanced the information effectively compared with the initial picture. Furthermore, compared with the other altered information, the contour line expression was strengthened.

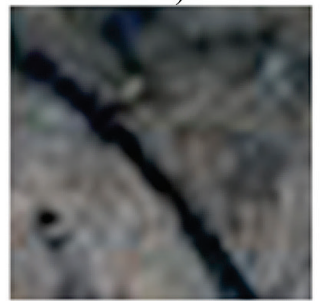

c)

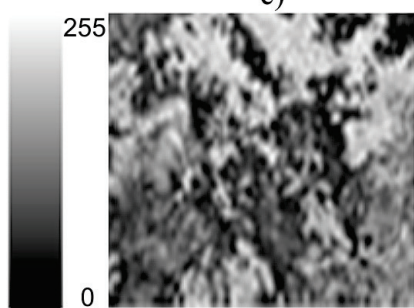

Figure 14 Classification images: a) Graphite sketch image; b) visible light image; c) Grey image of band math result; d) Classification image of band math result

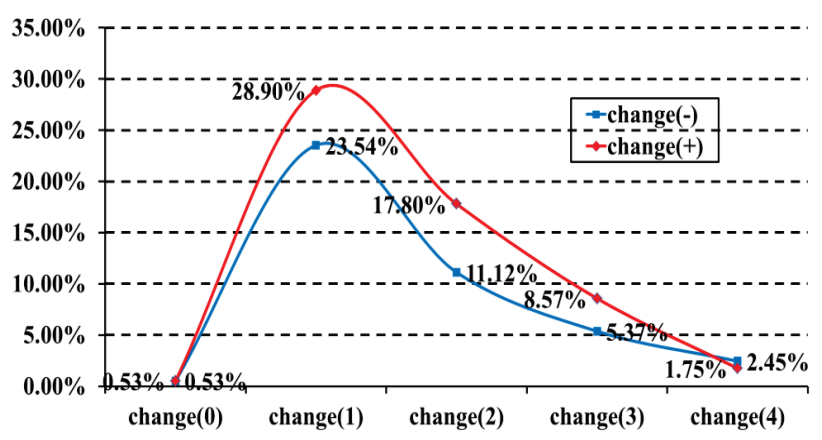

Figure 15 The percentage grey value change of the terminal fusion image

Table 4 Class attributes of the band math result image

\begin{tabular}{|c|c|c|c|c|c|c|c|}
\hline \multirow{2}{*}{ Class number } & Class name & Class interval & Pixel number & $\%$ & $\begin{array}{c}\text { Mean grey } \\
\text { value }\end{array}$ & SD & Colour \\
\hline Class 1 & change(+4) & {$[192,255]$} & 24335 & 1,75 & 213,7 & 18,1 & \\
\hline Class 2 & change(+3) & {$[128,192]$} & 119294 & 8,57 & 153,9 & 17,6 & \\
\hline Class 3 & change(+2) & {$[64,128]$} & 247939 & 17,80 & 92,3 & 18,4 & \\
\hline Class 4 & change(+1) & {$[0 \div 64]$} & 401749 & 28,90 & 30,5 & 18,2 & \\
\hline Class 5 & no change & {$[0,0]$} & 7410 & 0,53 & 0 & 0 & \\
\hline Class 6 & change(-1) & {$[-64,0]$} & 327717 & 23,54 & $-27,1$ & 17,9 & \\
\hline Class 7 & change(-2) & {$[-128,-64]$} & 154791 & 11,12 & $-90,9$ & 18,4 & \\
\hline Class 8 & change(-3) & {$[-192,-128]$} & 74702 & 5,37 & $-153,9$ & 18,1 & \\
\hline Class 9 & change(-4) & {$[-255,-192]$} & 34063 & 2,45 & $-212,1$ & 20,9 & \\
\hline
\end{tabular}

The images in Fig. 12 and Fig. 15 demonstrated that the current method is effective for extracting graphite contour line information using hyper-spectral data. In addition, the method can be applied to other objects not limited to murals, the results demonstrated that it had the necessary versatility for other remote sensing images, and was not limited to hyper-spectral data, and could realize good quality extract information.

\section{Discussion}

In this study, we have shown a novel method based on hyper-spectral data which can efficiently extract the graphite sketch of a mural, and can rehabilitate the original and completely reflect the real design concept of the painter. It was significant to trace and detect historically repaired marks. The graphite contour line was taken as the main research object in the experiment, a series of spectral analysis approaches was used to strengthen the expression of graphite information effectively. Although the results demonstrated that the scientific method can be widely used in the field of hyperspectral information extraction of different objects, the selection of two parameters restrained the accurate graphite information extraction. One threshold is determined in PPI calculation, it directly affected the accuracy of the reference spectral curve's formulation, and the reference spectrum determined the graphite information extraction in a certain degree. The other threshold appeared in graphite information classification; it determined the graphite information classification accuracy and ensured the integrity of graphite contour line. Synergistic reaction of two factors finally decided the generation of the graphite sketch and evaluation of the 
extraction quality. By providing our data evidence of threshold selection, we can explore the influences of different thresholds.

\subsection{Threshold in PPI calculation}

Pure pixel can be $N$ dimensional mapping three vertex graph iteration as a random unit vector to calculate the extreme pixels, each mapping was recorded, and the total values were recorded. In accordance with the number of multiple maps each pixel is recorded as an extreme pixel to decide whether the pixel is pure or not. $\mathrm{X}$ indicates pixel number of iterations, Y presents maximum pixel number. Fig. 16b shows the PPI calculation as a function of the number of iterations, when all the pure pixels are found, it should be close to a straight line. The higher value indicates the more purity pixels. The result of PPI (Pixel Purity Index) calculation is a grey image, where the bigger the DN (Digital Number) value indicates more pure pixels. Repeated iterations of each pixel in the image by pixel purity index method, can find the most pure pixels and high spectrum.

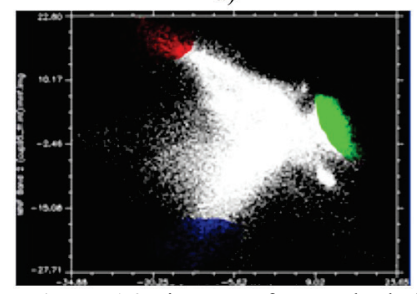

Figure 16 Diagram of PPI calculation processing: a) Two-dimensional scatter of pure pixel diagram; b) PPI iteration

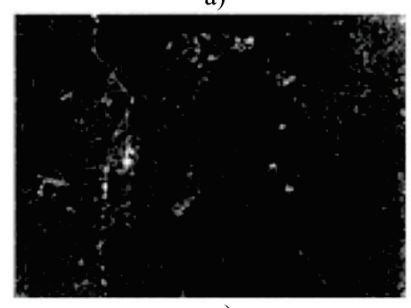

c)

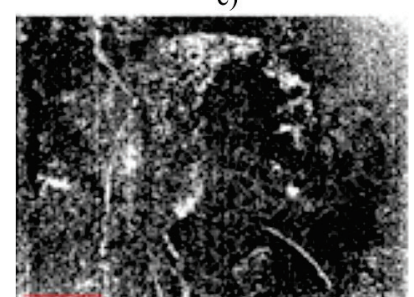
a) threshold 2,$25 ;$ b) threshold 2,50 ; c) threshold 2,$75 ;$ d) threshold 3,0

In the process of calculation, there are two significant parameters: the number of iterations and the threshold coefficient. In the test, the number of iterations is assumed constant and set to 2000 , we can detect the influence of threshold changes for the pure pixel extraction efficiency. Different thresholds were set in the PPI calculation processing to acquire the pure pixel distribution images. Generally speaking, only the value difference between DN and extreme pixel is greater than two digits, the corresponding pixel was marked as an extreme pixel. The threshold was selected pixel at the end of the mapping vector. The threshold should be $2 \div 3$ times the data noise level. For hyper-spectral data used in the experiments, the noise of the data is usually less than $1 \mathrm{DN}$ value, so when we calculated results based on input MNF image, the threshold was set from 2,0. The pure pixel distribution images based on different thresholds from $2,0 \div 3,0$ are shown in Fig. 17. The larger threshold would cause PPI calculation to find more extreme pixels (Fig. 18), but it also indicated that it also contained more mixed pixels, which influenced the accuracy of graphite curve extraction. The comparison of PPI calculation images based on different thresholds is shown in Fig. 16. Aimed at ensuring the purity of graphite information for extracting the clear contour line, comparing different PPI calculation images based on different thresholds in Fig. 17 , we select 2,75 as PPI calculation threshold for the next step of data processing.

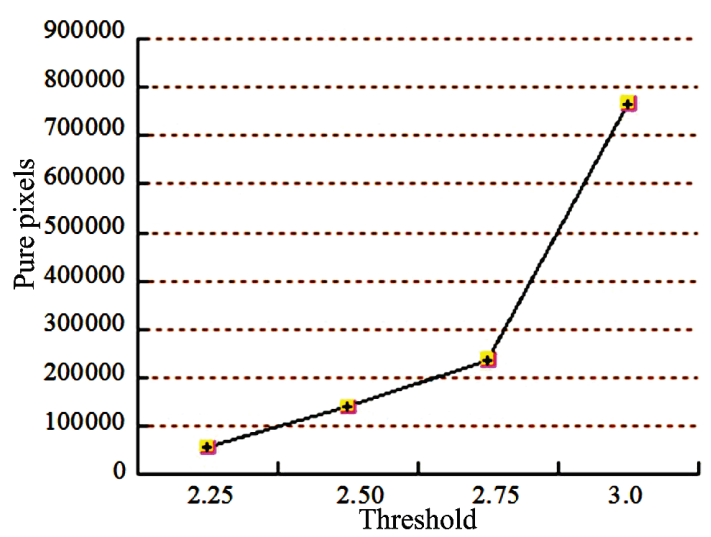

Figure 18 The numbers of pure pixels based on different thresholds

\subsection{Classification threshold in graphite information extraction}

The target of the study was to extract a graphite information image which contains the main contour line. Experiments in our study discovered that setting the maximum spectral angle threshold in SAM classification which was mentioned in Section 2 would have a greater impact on the classification results. We can explore the influence of classification thresholds based on the results presented here. Many experiments should be done to determine the threshold to achieve the maximum classification accuracy. After the pure pixels of the contour line were selected as the region of interest, the calculation result of average spectral curve was determined as the classification reference. When we set 0,1 as the single threshold for all information, the classified image was shown in Fig. 19a. Considering the existence of mixed pixels caused by interference with other pigments, even though the entire contour line was made of the same pigment, the spectral curve of each part of the contour line also has small difference. In order to classify more finely, the threshold generally should be respectively set to different values corresponding to different categories (if the threshold value was greater than the calculated spectral angle, the pixel was not classified). The contour line was divided into three parts: clothes, facial features and hair. After many comparative experiments, thresholds of three parts are set respectively 0,$1 ; 0,15 ; 0,2$ as shown in Fig. 19 (b). 
a)



Figure 19 Graphite contour line extraction image: a) single threshold 0,$1 ;$ b) multiple threshold 0,$1 ; 0,15 ; 0,2$
In order to evaluate the accuracy of classification, the confusion matrix was used to quantify the classification result. The classification precision of contour line based on graphite information was shown in Tab. 5.

Table 5 Classification precision statistics based on different thresholds

\begin{tabular}{|c|c|c|c|c|c|}
\hline \multirow{2}{*}{ 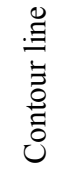 } & \multicolumn{4}{|c|}{ Multiple thresholds } & \multirow{2}{*}{ 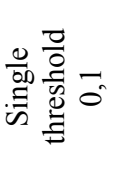 } \\
\hline & $\begin{array}{c}\text { Clothes } \\
0,1\end{array}$ & $\begin{array}{c}\text { Hair } \\
0,2\end{array}$ & $\begin{array}{c}\text { Facial } \\
\text { features } \\
0,15\end{array}$ & Average & \\
\hline 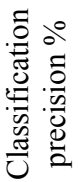 & 90,2 & 89,6 & 85,3 & 88,4 & 82,1 \\
\hline
\end{tabular}

Compared with a single threshold, the experiment found that setting different thresholds corresponding with the different parts of a contour line in classification can improve the classification precision. Hyper-spectral image classification method based on generalized angle emphasizes the shape feature of the spectrum, compressed image spectrum information, improving the efficiency of image classification arithmetic. However, this method is directly based on mean vectors of pixels as the centre and simply uses the minimum angle as the classification criterion. It cannot reflect the statistical properties of the selected sample area perfect. Moreover, if the criterion is inaccurate classification calculating has a high correlation coefficient which was calculated from formula 2,3 and the reference spectra of the pixel may be mistakenly classified.

\section{Conclusion}

In summary, we have shown a novel method used in extracting a clear mural's graphite sketch extraction, invisible spectra, particularly near-infrared (NIR) bands were used to detect the graphite information and strengthen the features of mural information to acquire a graphite sketch. The image processing involves pigment identification of contour line of mural, graphite spectral feature analysis, graphite information extraction and image fusion.

Based on spectral matching technology, spectral matching similarity of graphite with contour line and murals reached $90,3 \%$. It demonstrated that graphite is b)

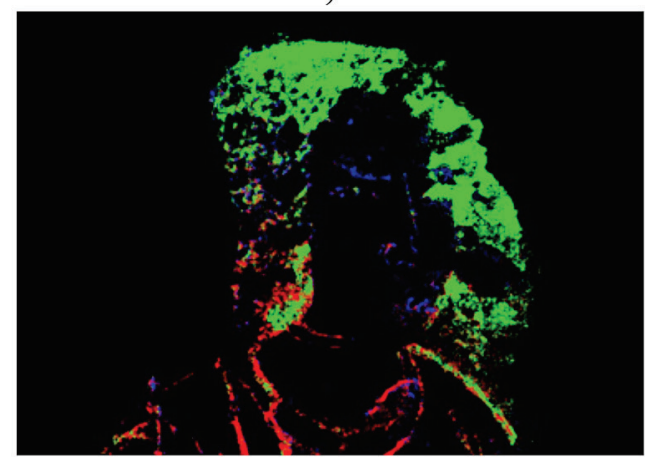

the main pigment of contour line for extracting the graphite sketch. The spectral feature of graphite was also analysed, the feature revealed that graphite had high absorption rate compared with other pigments in $800 \div$ 1000 band. Therefore, the 200 bands were selected as characteristics bands for extracting graphite information. The graphite information was extracted by a novel method, which involved PPI calculation and SAM classification; the paper explored the threshold in electing pure pixels PPI, the appropriate threshold 2,75 was determined by comparing different results based on different thresholds. In the processing of spectral angle mapping classification, the experiment revealed that compared to the single threshold, multiple thresholds can improve the classification accuracy, and the accuracy can reach $88,4 \%$. Finally, in order to evaluate the effect of extracting a graphite sketch, quantitative method based on $\mathrm{DN}$ was used. The DN value of fusion image and visible light image was calculated. It revealed brightness values of pixels found more reduced, the outcome image significantly enhanced the expression of graphite information.

These results demonstrated that the method was efficient for extracting graphite sketch based on hyperspectral data of mural. This graphite sketch extraction based on hyper-spectral data reports for the first time a unique signification of mural study in culture relic digital protection. This method provides a novel method to protect and restore murals, and also could provide useful information to explore cultural relics and to support some other protection researches. The current study revealed a method that blends the graphite contour line image with the original image to enhance the tomb mural visualization. It highlighted the target graphite information and also restrained the contamination in the background information to enhance the tomb mural visually. Although this method could enhance the mural from the whole image, it also revealed that the presence of the damage caused by human and nature factor impeded the expression of graphite information, and brought about the graphite sketch not complete and discontinuous. However, further study will be required to digitize virtual repairing graphite sketch defect.

\section{Acknowledgement}

The work was substantially supported by an award from the National Basic Research Program of China (973 
Program, under grant No. 2012cb725301) and National Natural Science Foundation of China (No. 41171304).

\section{References}

[1] Li, H. W.; Fu, C. W.; Hanson, A. J. Visualizing Multiwavelength Astrophysical Data. // IEEE Transactions on Visualization and Computer Graphics. 14, 6(2008), pp. 1555-1562. DOI: 10.1109/TVCG.2008.182

[2] Loghmari, M. A.; Naceur, M. S.; Boussema, M. R. A spectral and spatial source separation of multispectral images. // IEEE Transactions on Geoscience and Remote Sensing. 44, 12(2006), pp. 3659-3673. DOI: 10.1109/TGRS.2006.882261

[3] Goetz, A. F. H. Three decades of hyperspectral remote sensing of the Earth: A personal view. // Remote Sensing of Environment. 113, S.1(2009), pp. 5-16.

[4] Ma, Y. N.; Huang, M.; Yang, B.; Zhu, Q. B. Automatic threshold method and optimal wavelength selection for insect-damaged vegetable soybean detection using hyperspectral images. // Computers and Electronics in Agriculture. 106, 8(2014), pp. 102-110. DOI: 10.1016/j.compag.2014.05.014

[5] Uzair, M.; Mahmood, A.; Main, A. Hyper-spectral Face Recognition with Spatiospectral Information Fusion and PLS Regression. // IEEE Transactions on Image Processing. 24, 3(2015), pp. 1127-1137. DOI: 10.1109/TIP.2015.2393057

[6] Haneishi, H.; Ohtani, R.; Kouno, H. Multispectral image segmentation of paintings drawn with natural mineral pigments using the kernel based nonlinear subspace method. $/ / 15^{\text {th }}$ Color Imaging Conference Final Program and Proceedings. 2007, 1(2007), pp. 95-99.

[7] Daniilia, S.; Minopoulou, E.; Andrikopoulos, S. K.; Tsakalof, A.; Bairachtari, K. From Byzantine to postByzantine art: the painting technique of St Stephen's wall paintings at Meteora, Greece. // Journal of Archaeological Science. 35, 9(2008), pp. 2474-2485. DOl: 10.1016/j.jas.2008.03.017

[8] Chai, B. L.; Fan, Y. Q.; Su, B. M.; Wang, X. W. Investigating and studying the fading away wall paintings of Cave 194 at Mogao Grottoes with the UV induced fluorescence photography. // Dunhuang Reaearch. 124, 6(2010), pp. 74-76.

[9] Hain, M.; Bartl, M.; Jacko, V. Multispectral Analysis of Cultural Heritage Artefacts. // Measurement Science Review. 3, 3(2003), pp. 9-12.

[10] Kim, J. S.; Deng, F.; Brown, S. M. Visual enhancement of old documents with hyper-spectral imaging. // Pattern Recognition. 44, 7(2011), pp. 1461-1469. DOl: 10.1016/j.patcog.2010.12.019

[11] Lu, J. W. Data-driven digital drawing and painting.// dissertation for the degree of doctor of computer engineering, America, Princeton University, 2014.

[12] Zhang, B.; Gao, J. W.; Gao, L. R.; Sun, X. Improvements in the ant colony optimization algorithm for endmember extraction from hyper-spectral images. // Applied Earth Observations and Remote Sensing. 6, 2(2013), pp. 522-530. DOI: 10.1109/JSTARS.2012.2236821

[13] Lau, D.; Villis, C.; Furman, S.; Livett, M. Multispectral and hyperspectral image analysis of elemental and microRaman maps of cross-sections from a $16^{\text {th }}$ century painting. // Analytica Chimica Acta. 610, 1(2008), pp. 15-24. DOl: 10.1016/j.aca.2007.12.043

[14] Dópido, I.; Villa, A.; Plaza, A.; Gamba, P. A quantitative and comparative assessment of unmixing-based feature extraction techniques for hyper-spectral image classification. // Applied Earth Observations and Remote Sensing. 5, 2(2012), pp. 421-435. DOl: 10.1109/JSTARS.2011.2176721
[15] Hou, M. L.; Yang, S.; Hu, Y. G.; Wu, Y. H.; Shu, Z. Q.; Zhang, X. D. A novel method for the virtual restoration of cultural relics based on a 3D fine model. // DYNA, 90, 3(2015), pp. 307-313.

\section{Authors' addresses}

Xiaomeng Han

1) Beijing University of Civil Engineering and Architecture, Beijing, China

2) Beijing Institute of Surveying and Mapping, Beijing, China No. 15 Yangfangdian Road,Beijing, China, ZIP code: 100089 E-mail: hxm3059826@126.com

Miaole Hou, Ph.D., Professor (Corresponding author) 1) Beijing University of Civil Engineering and Architecture, Beijing, China.

2) University of Washington, Seattle, WA, U.S.A.

No. 1 Zhanlanguan Road, Beijing, China, ZIP code: 100044

E-mail: houmiaole@163.com

Guang Zhu, Professor

Beijing University of Civil Engineering and Architecture, Beijing, China

No. 1 Zhanlanguan Road, Beijing, China, ZIP code: 100044 E-mail: zhuguang@public.bta.net.cn

\section{Yungang $\mathrm{Hu}$, Professor}

Beijing University of Civil Engineering and Architecture, Beijing, China

No. 1 Zhanlanguan Road, Beijing, China, ZIP code: 100044 E-mail: hyg@bucea.edu.cn

\section{Xinfeng Ding}

Beijing University of Civil Engineering and Architecture, Beijing, China

No. 1 Zhanlanguan Road, Beijing, China, ZIP code: 100044 E-mail: dxf321@126.com 